\title{
The prognostic value of histopathological pattern of the pelviureteric junction in the outcome of pyeloplasty in children
}

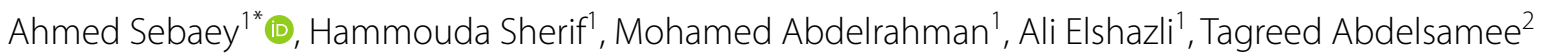 \\ and Tarek Gharib?
}

\begin{abstract}
Background: The cause of pyeloplasty failure remains unclear; therefore, increasing interest has been directed to identify the reason for dissatisfactory surgical results. Some studies attempted to investigate the role of the histopathological pattern. The aim of the work is to study the correlation between the histopathological pattern of obstructed pelviureteric junction (PUJ) segment and the outcome of pyeloplasty in children with the PUJ.
\end{abstract}

Methods: Fifty-four patients with pelviureteric junction obstruction (PUJO) were included in the study; patients were evaluated preoperative. All patients were operated by the same surgeon using Anderson-Hynes pyeloplasty; the resected obstructed PUJ segment examined histopathological using light microscope and image analyzer system to identify mean renal pelvis smooth muscle thickness (mRPSMT), collagen-to-smooth muscle ratio and elastin content.

Results: The study includes 50 patients with mean age Mean $24.48 \pm 15.3$ months. Two patients show no improvement, while 24 improved at 3 months, 16 improved at 6 months, and 8 improved at 12 months. mRPSMT showed significant difference between improvement groups (136.02 $\pm 44.4,173.47 \pm 49.69$ and $258.56 \pm 96.82 \mu \mathrm{m})$, while elastin content or collagen-to-smooth muscle ratio showed no significant difference.

Conclusions: Our data showed a clear relationship between mRPSMT and the time over which radiological improvement occurs; increase in mRPSMT is associated with a delay in postoperative radiological improvement time. We found no relation between elastin content nor collagen-to-smooth muscle thickness and postoperative improvement course.

Keywords: PUJO, Pyeloplasty, Histopathology

\section{Background}

Hydronephrosis caused by congenital pelviureteric junction obstruction (PUJO) is the most common urinary tract anomaly in childhood [1], affecting $1 / 1000-1 / 2000$ of newborns [2]. The incidence of PUJO diagnosis is expected to be gradually increased secondary to the widespread use of maternal ultrasound [3]. Until recently, the underlying mechanism of PUJO is still unclear.

\footnotetext{
*Correspondence: asebaey@yahoo.com

${ }^{1}$ Urology Department, Faculty of Medicine, Benha University, Benha,

Egypt

Full list of author information is available at the end of the article
}

Smooth muscle discontinuity or disproportionate presence of longitudinal smooth muscle fibers, together with excessive collagen deposition, has been suggested to be associated with the pathogenesis of congenital PUJO [4, 5].

Open dismembered pyeloplasty "Anderson-Hynes technique" has been considered the gold standard for treatment of PUJO for the last 70 years [6]. This technique was reported to be successful in a greater than $95 \%$ of patients. However, the remaining $5 \%$ still suffer from failure of procedures and the need for additional interventions to treat persistent obstruction $[7,8]$. On the other hand, the exact time to evaluate postoperative 
improvement using radiographic examinations is still unexpected, resulting in long-term, difficult and subjective clinical follow-up of patients [9].

Several different causes are known to be related to initially unresolved hydronephrosis, including irreversible histopathological changes in the renal pelvis and caliceal collecting system, transient obstruction due to edema at the site of repair and persistent obstruction due to failed pyeloplasty [3]. Unfortunately, the cause of pyeloplasty failure remains unclear; therefore, increasing interest has been directed to identify the reason for dissatisfactory surgical results. Some studies attempted to investigate the role of the histopathological pattern of the PUJ in this failure; however, its role is still controversial [10]. So, we attempted to conduct a prospective study to investigate the effect of the histopathological pattern of the ureteropelvic junction on the outcome of pyeloplasty in children with PUJO.

\section{Methods}

This is a prospective single arm study of patients submitted to pyeloplasty due to PUJO at the department of Urology, between January 2016 and June 2018. The study was approved by the local ethical committee of our university. All patients' parents provided written consent before participating in any study-related procedures.

The target population included patients diagnosed with PUJO. All patients with recurrent PUJO, any other urinary tract pathologies, active urinary tract infection (UTI), upper urinary tract congenital anomalies and vesicoureteric reflux were excluded.

Preoperative patient evaluation was performed including previous history, routine preoperative laboratory, renal ultrasound, intravenous urography, diuretic renogram and computerized tomography for urinary tract with contrast if indicated. All operations were performed by the same surgeon. All patients were operated using Anderson-Hynes pyeloplasty (dismembered pyeloplasty) [11], indwelling double-pigtail stent was placed for 6 weeks postoperative, and a drain was placed in the perinephric space. Histopathological specimen was obtained from obstructed PUJ site.

\subsection{Staining method}

All pathological assessments were examined at the department of pathology; specimens obtained for histopathological examination were fixed in $10 \%$ formalin. After fixation, the cleaned tissues underwent dehydration and buffering, and were embedded in paraffin. Blocks were cut into $4 \mu \mathrm{m}$ transverse serial whole amount section. In order to identify collagen and

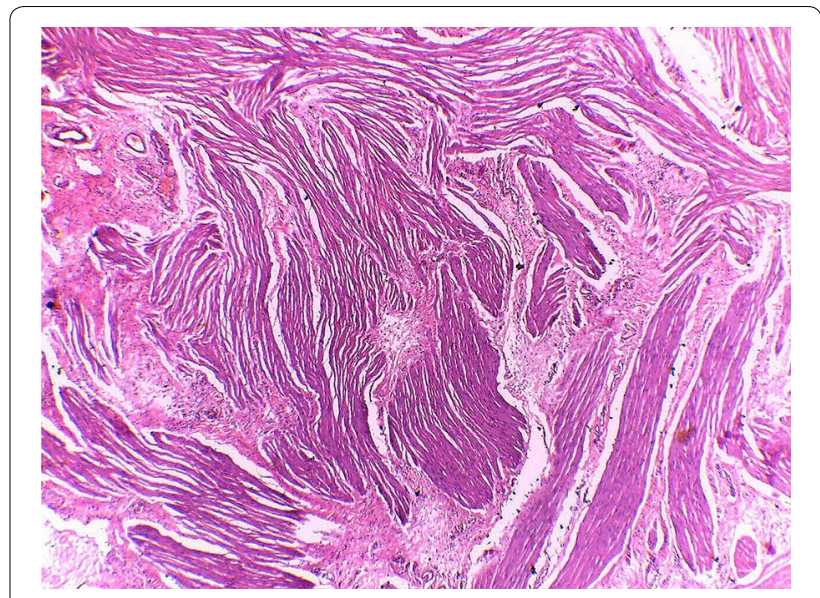

Fig. 1 Basophilic fibrocollagenous bundles in eosinophilic background "HX\&EOsin $\times 100$ "

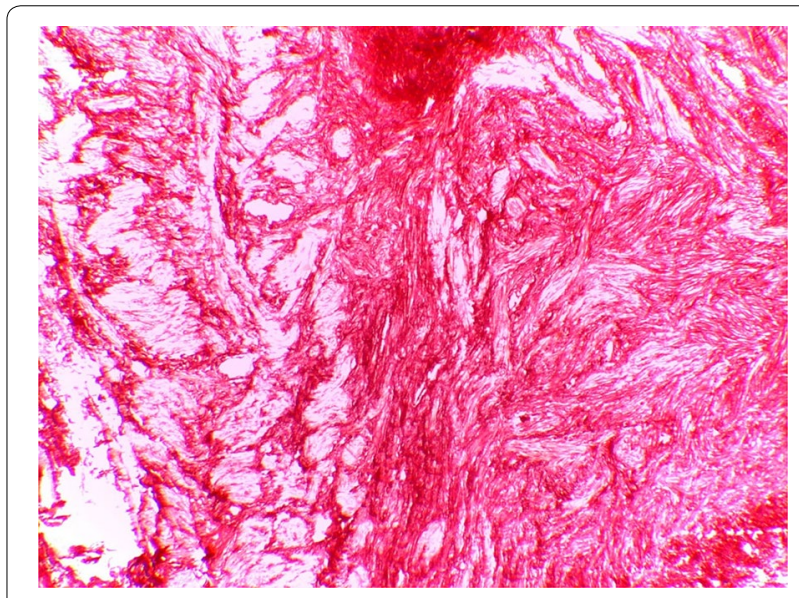

Fig. 2 Dark red-stained collagenous bundles in pink fibrohyaline background "syrus red $\times 100$ "

smooth muscle, sections were stained with hematoxylin and eosin stain and sirius red stain (Figs. 1, 2). Moreover, to identify elastin, sections were stained with Van Gieson's stain (Fig. 3). Finally, stained sections were examined under a light microscope and image analyzer system to determine the histopathological data including collagen-to-smooth muscle ratio, mean renal pelvis smooth muscle thickness and elastin content. By using image analyzer system which is computer software capable of obtaining quantitative data from histopathological sections of images, simply we determine the particular shape of the wanted parameter (elastin, collagen, smooth muscle); then, we ask the software to calculate the wanted data (percentage, ratio and mean 


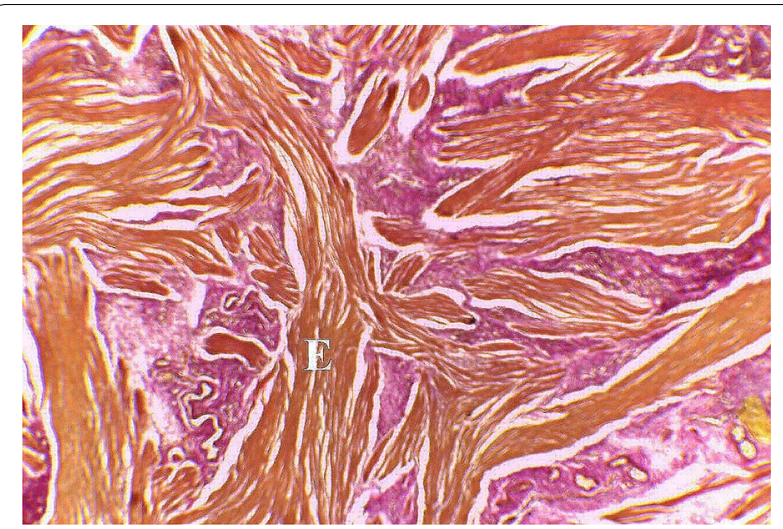

Fig. 3 Positive dark brown fibers of elastic tissue in eosinophilic background of fibrocollagenous bundles " $\times 200$-van gieson stain"; C collagen, E elastin

thickness) and then give us the data in numerical form not visual figures.

\subsection{Parameters estimated}

Age, gender, side of the lesion, time and results of postoperative radiographic examination, and time of definite improvement were identified in our study. All patients underwent a postoperative follow-up with a renal ultrasound $(\mathrm{U} / \mathrm{S})$ at the third month, the unresolved patients at sixth month and at twelfth month. The degree of improvement was defined as the difference between the preoperative and postoperative grades of hydronephrosis according to society of fetal urology (SFU) grading system. Diuretic renogram was used in selected cases when evaluation of prognosis by U/S could not be achieved.

\subsection{Statistical analysis}

Statistical analysis was performed using Statistical Package for the Social Science (SPSS Inc, Chicago, Illinois, USA) version 21.0. Patient characteristics were descriptively analyzed.

\section{Results}

Fifty-four patients were subjected to the study, but four patients missed from follow-up so they were excluded from the study.

So, 50 patients were assessed, and a total of 26 male and 24 female patients were identified (male to female ratio $1.08: 1$ ). The right-sided lesion was 26 , while leftsided lesion was 24 with ratio 1.08:1, mean BMI: body mass index was $22.96 \pm 3.36\left(\mathrm{~kg} / \mathrm{m}^{2}\right)$ ranging from 20 to 35 , mean age at operation was $24.48 \pm 15.3$ months with the youngest patient was 4 months and the oldest was 62 months, and the mean operative time was $89.4 \pm 23.4 \mathrm{~min}$.

According to SFU (society of fetal urology), there were 27 patients presented with grade III hydronephrosis, while 23 patients presented with grade IV hydronephrosis. Only two patients showed deterioration after removal of JJ stent, in the form of persistence of obstruction with increase in the hydronephrosis grade compared to the preoperative one, re-insertion of JJ stent failed, and the patients required re-operation (Table 1).

The rest of the patients showed improvement but varying in the time over which the improvement happened, and the improvement time ranged from 3 to 12 months.

Patients who had grade III hydronephrosis improved to grade II hydronephrosis, with 14 patients improved at 3 months, eight patients improved at 6 months, and four patients improved at 12 months. While patients with grade IV hydronephrosis improved to grade III; ten patients improved at 3 months, eight patients improved at 6 months, and four patients improved at 12 months (Tables 2, 3).

After statistical analysis, 24 patients improved at 3 months and had mRPSMT: mean renal pelvis smooth muscle thickness $136.02 \pm 44.4(\mu \mathrm{m})$, their collagen/ smooth muscle ratio $1.32 \pm 0.19$, and their elastin content was $17.13 \pm 3.13(\mu \mathrm{m})$, while 26 patient still with no improvement, 16 patients out of 26 improved at 6 months and had mRPSMT $173.47 \pm 49.69(\mu \mathrm{m})$ their collagen/smooth muscle ratio $1.31 \pm 0.23$, and their elastin content was $17.81 \pm 2.64(\mu \mathrm{m})$, while 10 patients still showed no improvement, after 12 months 8 patients out of 10 showed improvement with their

Table 1 Distribution of the studied group according to personal and histopathological data

\begin{tabular}{|c|c|}
\hline Variable & All $(N=50)$ \\
\hline Age/month Mean \pm SD (range) & $24.48 \pm 15.3(4-62)$ \\
\hline \multicolumn{2}{|l|}{ Sex no (\%) } \\
\hline Male & $26(52)$ \\
\hline Female & $24(48)$ \\
\hline \multicolumn{2}{|l|}{ Side no (\%) } \\
\hline Right & $26(52)$ \\
\hline Left & $24(48)$ \\
\hline Operative time (minutes) Mean \pm SD (range) & $89.4 \pm 23.4(60-120)$ \\
\hline $\mathrm{BMI}\left(\mathrm{kg} / \mathrm{m}^{2}\right)$ Mean $\pm \mathrm{SD}$ (range) & $22.96 \pm 3.36(20-35)$ \\
\hline mRPSMT ( $\mu \mathrm{m})$ Mean \pm SD (range) & $189.28 \pm 62.24(100-280)$ \\
\hline Collagen/muscle ratio Mean \pm SD (range) & $1.53 \pm 0.2(1.3-1.9)$ \\
\hline Elastin content $(\mu \mathrm{m})$ Mean \pm SD (range) & $18.48 \pm 1.49(16-22)$ \\
\hline
\end{tabular}

$B M I$ body mass index, $m R P S M T$ mean renal pelvis smooth muscle thickness 
Table 2 Grades of hydronephrosis preoperative and time of improvement

\begin{tabular}{lllll}
\hline $\begin{array}{l}\text { Grade of hydronephrosis } \\
\text { preoperative (no) }\end{array}$ & Improved at 3 months (\%) & Improved at 6 months (\%) & Improved at 12 months (\%) & $\begin{array}{l}\text { No } \\
\text { improvement } \\
\text { (\%) }\end{array}$ \\
\hline Grade III (27) & $14(51.85 \%)$ & $8(29.62 \%)$ & $4(14.81 \%)$ & $1(3.7 \%)$ \\
Grade IV (23) & $10(43.48 \%)$ & $8(34.78 \%)$ & $4(17.39 \%)$ & $1(4.35 \%)$ \\
\hline
\end{tabular}

Table 3 Number of patients improved after different follow-up period

\begin{tabular}{lc}
\hline Variable & No. (\%) \\
\hline Follow-up at 3 month: $N=50$ & \\
Improved no (\%) & $24(48)$ \\
Not improved no (\%) & $26(52)$ \\
Follow-up at 6 month: $N=26$ & \\
Improved no (\%) & $16(61.5)$ \\
Not improved no (\%) & $10(38.5)$ \\
Follow-up at 12 month: $N=10$ & \\
Improved no (\%) & $8(80)$ \\
Not improved no (\%) & $2(20)$ \\
\hline
\end{tabular}

Table 4 mRPSMT, collagen/smooth muscle and elastin after different follow-up periods

\begin{tabular}{lcccc}
\hline & Improvement & $\begin{array}{l}\text { No } \\
\text { improvement }\end{array}$ & St $\boldsymbol{t}$ test & P value \\
\hline mRPSMT $(\mu \mathrm{m})(\mathrm{mean} \pm \mathrm{SD})$ & & & \\
At 3m (month) & $136.02 \pm 44.4$ & $111.81 \pm 25.45$ & 2.39 & 0.021 \\
At $6 \mathrm{~m}$ & $173.47 \pm 49.69$ & $129.6 \pm 36.19$ & 2.41 & 0.024 \\
At $12 \mathrm{~m}$ & $258.56 \pm 96.82$ & $138.25 \pm 1.06$ & 1.68 & 0.13 \\
Collagen/smooth muscle (mean \pm SD) & & & \\
At 3m & $1.32 \pm 0.19$ & $1.33 \pm 0.20$ & 0.097 & 0.92 \\
At $6 \mathrm{~m}$ & $1.31 \pm 0.23$ & $1.36 \pm 0.13$ & 0.68 & 0.51 \\
At $12 \mathrm{~m}$ & $1.38 \pm 0.09$ & $1.30 \pm 0.28$ & 0.73 & 0.49 \\
Elastin content $(\mu \mathrm{m})(\mathrm{mean} \pm \mathrm{SD})$ & & & \\
At 3m & $17.13 \pm 3.13$ & $18.04 \pm 2.62$ & 1.12 & 0.27 \\
At $6 \mathrm{~m}$ & $17.81 \pm 2.64$ & $18.4 \pm 2.67$ & 0.55 & 0.59 \\
At $12 \mathrm{~m}$ & $18.25 \pm 2.82$ & $19.0 \pm 2.83$ & 0.34 & 0.75 \\
\hline
\end{tabular}

mRPSMT was $258.56 \pm 96(\mu \mathrm{m})$ their collagen/smooth muscle ratio $1.38 \pm 0.09$ and their elastin content was $18.25 \pm 2.82(\mu \mathrm{m})$, and 2 patients with no improvement at 12 months, we found correlation between mRPSMT and postoperative time of improvement but no correlation between elastin percentage and collagen-to-smooth muscle ratio to postoperative time of improvement (Table 4).

\section{Discussion}

Since first described by Anderson and Hynes in 1949, open dismembered pyeloplasty remains the gold standard for PUJO treatment [11]. In more than $95 \%$ of cases, this technique is successful [12]. In spite of this very high success rate, the period over which satisfactory non-obstructive pattern of renal function is usually not predictable. In some cases, the initial postoperative radiological investigation shows no signs of successful surgical correction. This is extremely stressful situation for both surgeon and patients (or their parents); however, most of these cases show spontaneous improvement by time. Thus, finding predictor of the outcome course is urgently needed.

Histological changes in the renal pelvis in response to obstruction determine its compliance after pyeloplasty $[1,3]$. Many studies-including our study-tried to correlate the outcome of the surgery with histopathological changes in the renal pelvis. Most of them focused on mRPSMT, collagen-to-smooth muscle ratio and elastin content of the renal pelvis.

In this study, our data showed a clear relationship between mRPSMT and the time over which radiological improvement occurs; increase in mRPSMT is associated with a delay in postoperative radiological improvement time. We found no relation between elastin content nor collagen-to-smooth muscle thickness and postoperative improvement course.

Issi and his colleagues studied the effect of histopathology of resected PUJ segment during pyeloplasty on the outcome of surgery; they found no difference in quantity collagen type 3 , elastin content, fibrosis, nor Cajal cells between the two study groups; group of immediate postoperative improvement and group of delayed improvement, so they concluded that none of these factors has impact on the outcome of surgery; this is supported by our data regarding elastin content and collagen [10].

In a trail to compare histologically between normal PUJ and PUJO, Doğan et al. studied number of interstitial cells, nerves, presence of fibrosis and inflammation in normal PUJ and PUJO, and they found no difference in these items between the two groups, so they concluded that none of these factors has a role in pathogenesis of PUJO [14]; on the other hand, some authors investigate 
the relation between the presence of interstitial cells in the resected segment of PUJ during pyeloplasty and the postoperative outcome, and they found that there is no interstitial cells found in the segments resected from cases that had bad surgical outcome [15].

We found statistically significant difference in the mean mRPSMT between improved and non-improved patient at 3, 6 month postoperative; however, this difference was not significant at 12 month and this was supported by Han et al., Kaselas et al. However in their study, they found positive correlation between MRPSMT and delayed postoperative radiographic improvement $[3,9]$.

Some reports showed increase in elastin content and correlate with delaying in postoperative improvement; this could be due to decrease elasticity and compliance $[12,16]$. Kim and his colleagues correlate between collagen-to-smooth muscle tissue matrix ratio in PUJO and the outcome of pyeloplasty; they observed that the lower the tissue matrix ratio, the better improvement of hydronephrosis postoperative [13], whereas we found no significant relation of elastin content nor collagen-tosmooth muscle ratio to postoperative recovery course.

Persistent obstruction associated with prolonged time interval should be a worrying sign for both the parents and the treating surgeon. We can finally conclude from our results that the information retrieved from the histopathological examination of the obstructed PUJ samples after a dismembered pyeloplasty has an important clinical implication to be considered and thus could be used as a prognostic factor. Patient's postoperative course and expected timing of hydronephrosis improvement, based on the thickness of their renal pelvis smooth muscle, should take much attention by the surgeon during the patient's postoperative recovery time and until the first postoperative radiographic examination. Taking the histopathological data into consideration could successfully help the surgeon to roughly estimate the expected time over which improvement occur.

The limitation of the study was relatively small number of patients.

\section{Conclusions}

Our study concluded that mRPSMT can be used as a significant indicator of postoperative prognosis course, while elastin content and collagen-to-smooth muscle ratio have no role in this; thus, we believe that mRPSMT can provide the surgeon with important prognostic factor which can help in prediction of postoperative course.

\section{Abbreviations}

PUJ: Ureteropelvic junction; PUJO: Ureteropelvic junction obstruction; mRPSMT: Mean renal pelvis smooth muscle thickness; UTI: Urinary tract infection; SFU: Society of fetal urology.

\section{Acknowledgements}

None.

\section{Authors' contributions}

AS and HS were involved in design of the work, performed the pyeloplasty, took the biopsy analysis and interpretation of data, have drafted the work and substantively revised it. MA has drafted the work and substantively revised it. AA contributed to design of the work and substantively revised it. TA was involved in design of the work, analysis and interpretation of data histological examination of the specimens. TG helped in design of the work, analysis, interpretation of data, have drafted the work and substantively revised it. All authors read and approved the final manuscript.

\section{Funding}

None.

\section{Availability of data and materials}

Authors can confirm that all relevant data are included in the article and/or its supplementary information files.

\section{Ethics approval and consent to participate}

All procedures performed in this study involving human participants were in accordance with the ethical standards of the institutional research committee in Benha Faculty of Medicine; the reference number is not applicable.

\section{Informed consent}

Informed consent was obtained from all individual participants included in the study.

\section{Consent for publication}

Not applicable.

\section{Competing interests}

The authors declare that they have no competing interest.

\section{Author details}

${ }^{1}$ Urology Department, Faculty of Medicine, Benha University, Benha, Egypt.

${ }^{2}$ Pathology Department, Benha Faculty of Medicine, Benha University, Benha, Egypt.

Received: 30 October 2019 Accepted: 14 July 2020

Published online: 20 September 2020

\section{References}

1. Hennessey DB, Kinnear NJ, Evans RM, Hagan C, Thwaini A (2017) Is confirmation of ureteric stent placement in laparoscopic pyeloplasty necessary? Int Urol Nephrol 49(6):931-936

2. Hosgor M, Karaca I, Ulukus C, Ozer E, Ozkara E, Sam B, Ucan B, Kurtulus S, Karkıner A, Temır G (2005) Structural changes of smooth muscle in congenital ureteropelvic junction obstruction. J Pediatr Surg 40(10):1632-1636

3. Kaselas C, Aggelidou S, Papouis G, Kazakis C, Philippopoulos A (2011) Thickness of the renal pelvis smooth muscle indicates the postoperative course of ureteropelvic junction obstruction treatment. Actas Urológicas Españolas (English Edn) 35(10):605-609

4. Chevalier RL, Forbes MS, Thornhill BA (2009) Ureteral obstruction as a model of renal interstitial fibrosis and obstructive nephropathy. Kidney Int 75(11):1145-1152

5. Chevalier RL, Thornhill BA, Forbes MS, Kiley SC (2010) Mechanisms of renal injury and progression of renal disease in congenital obstructive nephropathy. Pediatric Nephrol 25(4):687-697

6. Chan YY, Durbin-Johnson B, Sturm RM, Kurzrock EA (2017) Outcomes after pediatric open, laparoscopic, and robotic pyeloplasty at academic institutions. J Pediatr Urol 13(1):49-e1

7. Bonnard A, Fouquet V, Carricaburu E, Aigrain Y, El-Ghoneimi A (2005) Retroperitoneal laparoscopic versus open pyeloplasty in children. J Urol 173(5):1710-1713

8. Reed MJ, Williams MP (2003) Open pyeloplasty in children: experience with an improved stenting technique. Urol Int 71(2):201-203 
9. Han SW, Maizels M, Chou PM, Fernbach SK, Cheng EY, Furness III PD (2001) Lamina muscularis propria thickness of renal pelvis predicts radiological outcome of surgical correction of ureteropelvic junction obstruction. J Urol 165(5):1648-1651

10. Issi O, Deliktas H, Gedik A, Ozekinci S, Bircan MK, Sahin H (2015) Does the histopathologic pattern of the ureteropelvic junction affect the outcome of pyeloplasty? Urol J 12(1):2028-2031

11. Anderson JC, Hynes W (1949) Retrocaval ureter: a case diagnosed pre-operatively and treated successfully by a plastic operation. Br J Urol 21(3):209-214

12. Kim DS, Noh JY, Jeong HJ, Kim MJ, Jeon HJ, Han SW (2005) Elastin content of the renal pelvis and ureter determines post-pyeloplasty recovery. J Urol 173(3):962-966

13. Kim WJ, Yun SJ, Lee TS, Kim CW, Lee HM, Choi H (2000) Collagen-tosmooth muscle ratio helps prediction of prognosis after pyeloplasty. J Urol 163(4):1271-1275

14. Doğan HT, Canda AE, Gök B, Oğuz U, Gümüştaş S, Atmaca AF, Vargöl E (2018) Is there a difference in the number of interstitial cells, neurons, presence of fibrosis and inflammation in ureteropelvic junction tissues of patients with ureteropelvic junction obstruction with and without crossing vessels? Turk J Urol 45:302-306

15. Inugala A, Reddy RK, Rao BN, Reddy SP, Othuluru R, Kanniyan L, Kumbha $\mathrm{N}$, Srirampur S (2017) Immunohistochemistry in ureteropelvic junction obstruction and its correlation to postoperative outcome. J Indian Assoc Pediatr Surg 22(3):129

16. Fernández-Ibieta M, Nortes-Cano L, Guirao-Piñera MJ, ZambudioCarmona G, Ruiz-Jiménez JI (2016) Radiation-free monitoring in the long-term follow-up of pyeloplasty: are ultrasound new parameters good enough to evaluate a successful procedure? J Pediatr Urol 12(4):230-e1

\section{Publisher's Note}

Springer Nature remains neutral with regard to jurisdictional claims in published maps and institutional affiliations.

\section{Submit your manuscript to a SpringerOpen ${ }^{\odot}$ journal and benefit from:}

- Convenient online submission

- Rigorous peer review

- Open access: articles freely available online

- High visibility within the field

- Retaining the copyright to your article

Submit your next manuscript at $\gg$ springeropen.com 